\title{
Bioactive Compounds of Acai (Euterpe oleracea) and the Effect of their Consumption on Oxidative Stress Markers
}

\author{
Romel Guzmán ${ }^{1, *}$, Ricardo Aponte $^{1}$ and Mary Lares ${ }^{2}$ \\ ${ }^{1}$ Institute of Food Science and Technology (ICTA), Faculty of Sciences, Central University of Venezuela \\ (UCV), Caracas, Venezuela \\ ${ }^{2}$ School of Nutrition and Dietetics, Faculty of Medicine, UCV and Department of Endocrinology and Metabolic \\ Diseases, Military Hospital "Dr. Carlos Arvelo", Caracas, Venezuela
}

\begin{abstract}
Açaí fruit (Euterpe oleracea Martius) is highly perishable, so it sought to apply conservation techniques that make its commercialization more bearable such as dehydration by the tray. This thermal technique that significantly inactivates harmful enzymes and microorganisms prolongs their shelf life but has the disadvantage that it decreases the proportion of bioactive components and its antioxidant power. The present work aims to estimate the content and antioxidant activity of the bioactive compounds of açaí powder supplied in hydroxypropyl methylcellulose (HPMC) vegetable capsules. For this purpose, total polyphenols were determined by the Folin-Ciocalteau test, total anthocyanin's by the differential $\mathrm{pH}$ test, and the antioxidant capacity in vitro DPPH method (using Trolox and Vitamin $\mathrm{C}$ equivalent). Also, the effect of consumption of four daily capsules on a healthy population (10 people) between the ages of 33-65 years old evaluated through a 10-day intervention study in which the following biomarkers in blood assessed: glycemia, triglycerides, total cholesterol, HDL, LDL, and 8-isoprostane. The açaí powder showed a total polyphenol content of $962.7 \pm 22.2 \mathrm{mg} \mathrm{EAG} / 100 \mathrm{~g}$, total anthocyanin's up to $938.5 \pm 19.1 \mathrm{mg} \mathrm{C} 3 \mathrm{GE} / 100 \mathrm{~g}$, the antioxidant capacity of $643 \pm 24.32$ $\mu \mathrm{mol} T E / 100 \mathrm{~g}$ and $14.07 \pm 0.45 \mathrm{~g}$ VCE$/ 100 \mathrm{~g}$. In the intervention study, no significant differences were observed between before and after the different biochemical markers except for 8-isoprostane, suggesting that the consumption of dehydrated açaí caused effects benefices in the population tested.
\end{abstract}

Keywords: Açaí, bioactive compounds, antioxidant capacity, oxidative stress, intervention study.

\section{INTRODUCTION}

Euterpe oleracea Martius, commonly known as açaí, is a palm tree indigenous from the Amazonian region found in dense concentrations. This palm grows in Brazil, Colombia, Paraguay, Argentina, the Guianas, Venezuela, and Bolivia [1-3]. In the 90s was discovered that açaí berry had very high antioxidant properties in vitro, this fact causes the development of a vast industry over the years to supply açaí fruit for export in Brazil. By the year 2009, açaí had gained so much popularity that it became the top "superfood" among the rest of the fruits due to its extraordinary oxygen radical absorbance capacity (ORAC) assay value. In part, this antioxidant capacity is owed to polyphenols content in açaí fruit. Polyphenols are secondary metabolites widely distributed in the plant kingdom. Structural characteristics give these compounds the ability to reduce the risk of certain diseases by consuming foods and beverages containing them [4]. Among the diseases in which polyphenols exert positive health changes are: cardiovascular and neurodegenerative diseases, hormonal disorders, obesity, diabetes, and cancer. For this reason, polyphenols have been increasingly studied, so their

*Address correspondence to this author at the ICTA calle Suapure, Colinas de Bello Monte, Municipio Baruta, Miranda, Distrito Capital, Venezuela;

Tel: +58 212 7534403; E-mail: romelguzman@gmail.com health-promoting properties can be extensively applied in humans prolonging the life cycle [5].

Metabolic syndrome is a collection of risk factors as diabetes and cardiovascular diseases associated with a pro-inflammatory state. This syndrome avoids the body antioxidant's incapacity to neutralize oxidative stress by excessive free radical's production [6]. Polyphenols protect against cardiovascular diseases through several mechanisms, mainly their capacity to scavenge oxygen-derived free radicals, acting as reducing and chelating agents, chain-breaking antioxidants, quenchers of singlet oxygen formation, and protecting ascorbic acid, and so forth [7]. Clinical studies support the beneficial effect of dietary intervention with various polyphenol-rich foods on blood lipids and glycemic measures changes. They also play a role in lipid metabolic disorders, which are the pathologic antecedents of atherosclerosis. Regarding açaí, a series of studies have also made about diet supplementation with açaí showing improvement of oxidative stress biomarkers in animals $[8,9]$ and humans $[10,11]$.

Açaí fruit degrades rapidly, mainly its phytochemicals content because of polyphenol oxidase and peroxidase activity. Therefore, açaí berries have to be processed quickly and under low temperatures. Açaí pulp that is frozen continues to 
degrade as opposed to the pulp that is dehydrated to inhibit the rate of enzymatic degradation [12]. The best process to dehydrate is freeze-drying that maintains its full bioactivity. Also, spray-drying and conventional drying are used, but these techniques preserving a little bit less bioactivity. Conventional drying has disadvantages, prolonged times, heat, and oxygen exposure, but this process allows the producers of less developed regions to preserve higher production amounts at cheaper costs. This study aims to assess if açaí fruit processed by tray-drying preserve enough polyphenols amount, antioxidant capacity in vitro and in vivo so it would be economically and technically reasonable to process açaí this way.

\section{MATERIALS AND METHODS}

\section{Açaí Pulp, Powder, and Capsules}

Açaí berries harvested in Amazonas and Bolivar state; Venezuela then transported, cleaned, and frozen into a manufacturing facility in Amazonas state, Venezuela. The next day fruits were processed to pulp and stored at $-10^{\circ} \mathrm{C}$. Next, it was transported to the laboratory where part of it was dehydrated on a tray dehydrator (Mitchel dryers 6451/59) until constant weight at $45 \pm 5^{\circ} \mathrm{C}$ temperatures and converted to powder using a standard grain grinder (ZXMOTO $700 \mathrm{~g}$ Electric grain grinder). The powder was finally packed in hermetic bags and kept at $-10^{\circ} \mathrm{C}$ until analyzed. The powder was encapsulated in commercial HPMC capsules, size "0" using a manual 100 holes capsules filling machine (chengzhijingmi) under aseptic conditions, and packed on hermetic Mylar bags then stored at $-10^{\circ} \mathrm{C}$ Until intervention study was done.

The chemical composition was determined according to [13] moisture method 925.10, lipid method 920.39, ash method 923.03, nitrogen method 920.87, and carbohydrates by difference. Bulk and tapped density of açaí powder measured according to [14] following method I for both densities using $250 \mathrm{~mL}$ graduated cylinder next Hausner index was calculated with previously obtained values.

\section{Microbiological Analysis}

The following tests realized in açaí capsules: total aerobic microbial count, total combined yeast and molds count, bile tolerant Gram-negative bacteria, and absence of Salmonella spp and E. coli, as recommended on Nutritional and Dietary Supplements [15] for dried or powdered botanicals. Proceedings described in chapters 2021 and 2022 of the same norm.

\section{Extraction of Polyphenolics Fractions}

Açaí aqueous extract was prepared by diluting açaí pulp and previously prepared açaí powder in pure methanol for total polyphenols and antioxidant capacity tests. For the anthocyanin's test, two extracts prepared using acidified methanol at $0.1 \%$ (buffer $\mathrm{pH}=1$ ) and sodium acetate buffer $(\mathrm{pH}=4.5)$. These solutions placed in a shaker for 60-minute intervals (for total polyphenols and antioxidant capacity) and 45 minutes (total anthocyanin's), centrifuged at 3000rpm during $10 \mathrm{~m}$, the upper lipid phase of centrifuge tubes discarded, and the rest of the supernatant filtered through a \#2 Whatman paper. Upon filtration, the extracts were immediately analyzed.

\section{Total Polyphenols Content}

Phenolic extract previously prepared was used for total polyphenols determination using Folin-Ciocalteau assay [16] and quantified against a Gallic acid standard curve. A $0,1 \mathrm{~mL}$ aliquot of extract or standard was mixed with $7 \mathrm{~mL}$ of distilled water followed by $0,5 \mathrm{~mL}$ of Folin-Ciocalteau reagent. After the solution mixed and incubated (1 to 8 minutes), were added $1,5 \mathrm{~mL}$ of a $20 \%$ sodium carbonate solution and $0,9 \mathrm{~mL}$ of distilled water. Remixed and left to stand for 2 hours at approximately $20^{\circ} \mathrm{C}$. Finally, absorbance was determined at a wavelength of $765 \mathrm{~nm}$. The results were expressed as $\mathrm{mg}$ Gallic acid equivalents per $100 \mathrm{~g}$ sample in fresh and dry weight (mg GAE/100g).

\section{Total Anthocyanin's Content}

Anthocyanin content was determined in the previously prepared extracts using the $\mathrm{pH}$ differential method, as described by [17] with some modifications. Absorbance was determined at 510 and $700 \mathrm{~nm}$. Results expressed as mg cyanidin-3-glucoside $/ 100 \mathrm{~g}$ sample in fresh and dry weight.

\section{Antioxidant Activity}

Antioxidant activity was assessed by the DPPH assay $[18,19]$ with modifications based on the reduction of the free radical 2,2'-diphenyl-1-picrylhydrazyl (DPPH). Trolox and ascorbic acid are used as reference antioxidants. A standard solution of $35 \mathrm{mg} / \mathrm{L}$ DPPH in absolute methanol was prepared daily and stored in a bottle protected from light. A $0.1 \mathrm{~mL}$ aliquot of extract or standard added to test tubes (protected 
from light) containing $3.9 \mathrm{~mL}$ of $\mathrm{DPPH}$ solution and gently mixed. Absolute methanol is used as a negative control. At $515 \mathrm{~nm}$ was determined (immediately), the absorbance in control for the rest of the tubes was determined every 10 minutes. The relative DPPH scavenging capacities were expressed as micromoles of Trolox Equivalents (TE) per $100 \mathrm{~g}$ sample ( $\mu \mathrm{mol}$ TE $1100 \mathrm{~g}$ ) and milligrams of vitamin $\mathrm{C}$ equivalents (VCE) per $100 \mathrm{~g}$ sample (mg VCE/100g) [20] and as a percentage of residual DPPH at a constant state. Residual DPPH percentage was assessed according to the following equation:

$$
\% \mathrm{R}=\mathrm{DPPHf} \mathrm{DPPHi} \text { * } 100
$$

Where, DPPHf means absorbance of DPPH radical at a constant state, and DPPHi means absorbance of $\mathrm{DPPH}$ at $0 \mathrm{~m}$.

\section{Stability Analysis}

Açaí capsules were stored in airtight high-density polyethylene (Mylar) bags under stress and accelerated conditions $\left(40 \pm 1^{\circ} \mathrm{C}\right)$ for three months, next, samples were analyzed for: total polyphenols, total anthocyanin's, and antioxidant capacity. Results expressed as increasing/decreasing percentages based on the initial and final values of the previously mentioned assays.

\section{Anthropometric and Biochemical Markers}

A dietary intervention study was carried out with the participation of ten healthy volunteers without distinction between sexes and ages between 33 and 65 years old. Volunteers with pathologies of chronic diseases, diabetes, infections, immunological diseases, obesity treated with surgery, pregnant women were excluded from the study. Those who are have been prescribed antihypertensive drugs were excluded too. All volunteers did sign an informed consent form. This study was approved by the Ethics Committee of the Military Hospital "Dr. Carlos Arvelo" and conducted at the same location (Caracas, Venezuela). The study complied with the guidelines provided by the Declaration of [21]. Also, a survey was conducted among the participants to assess their food frequency consumption. Participants were instructed to consume four (4) açaí capsules per day for ten days, preferably with their regular daily meals, and avoid consuming polyphenols-rich foods like wine and chocolate. It was extracted $30 \mathrm{~mL}$ of peripheral blood in fasting conditions right at the beginning and the end of the ten-day açaí consumption period. The blood samples were analyzed for plasma glucose, cholesterol, triglycerides, HDL, LDL, and 8-isoprostane using standard commercial enzymatic colorimetric methods except for isoprostane, which was performed by Elisa using a CaymanChemical commercial kit. The following anthropometric measurements were also taken at the beginning and the end of the study: weight, height, body mass index, and waist to hip ratio using the methodology of the International Biology Program [22] and bio-impedance scale.

\section{Statistical analysis}

Every experiment was realized per triplicate (except in vivo analyses) and expressed as mean values with the respective standard deviation. Statistical analyses were using paired Student's t-test on the intervention study. All statistics were based on a confidence level of $95 \%$, and $p<0.05$ was considered statistically significant [23].

\section{RESULTS}

\section{Proximate Composition}

The water content of the açaí pulp of $78.98 \% \pm 0.11$ was obtained, which indicates that its solids are approximately $21 \%$, a concentration that is higher than the commercial açai pulp products marketed today. Some of which were analyzed in this study and yielded full contents of $14 \%$ solids. The drying curve showed that at 300 minutes, the pulp reached stability (Figure 1). The powder obtained from the size reduction of the açaí solids yielded a water content of $8.46 \% \pm 0.11$. Acai powder (Table 1) is mainly composed of carbohydrates, similar to that reported in the literature [24-27].

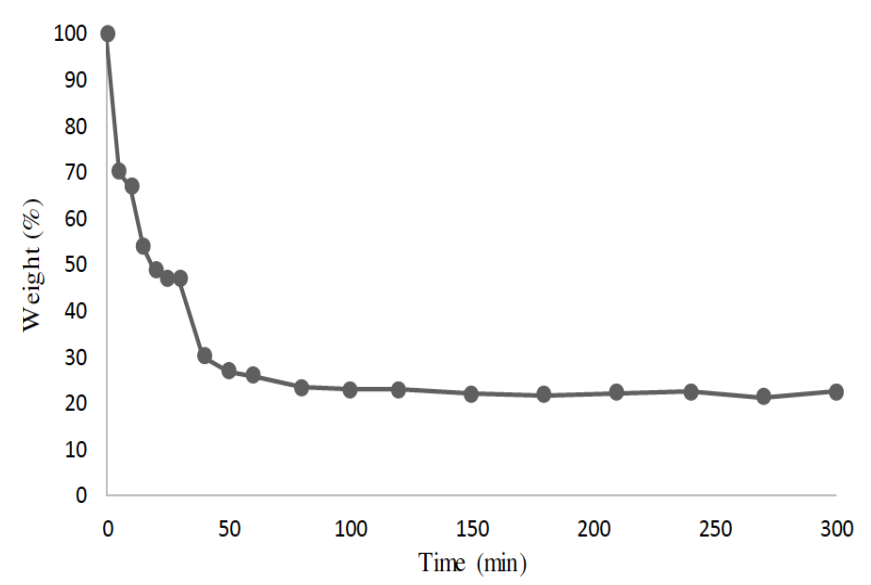

Figure 1: Drying curve of açaí pulp at a temperature of $45 \pm$ $1^{\circ} \mathrm{C}$ during 300 minutes. 
Table 1: Proximate Composition of Dehydrated Açaí on a Dry Basis

\begin{tabular}{|c|c|}
\hline Components & Contents per 100g \\
\hline \hline Ashes & $2.23 \pm 0.05$ \\
\hline Protein $^{\star}$ & $9.23 \pm 0.13$ \\
\hline Fat & $36.40 \pm 0.48$ \\
\hline Carbohydrates & $52.13 \pm 0.01$ \\
\hline Energy & $59.12 \pm 0.01$ \\
\hline
\end{tabular}

Analyses were performed in triplicate, and the results are expressed on a dry weight basis as means \pm standard deviations.

*Conversion factor used to calculate protein content: $\mathrm{N}=6.25$

Energy is expressed as $\mathrm{KJ} / 100 \mathrm{~g}$.

\section{Microbiological Analysis}

Analysis microbiological was carried out to know the quality and guarantee its safety to consumers. Table 2 shows the results of microbial counts of açaí capsules. Obtained very low counts for fungi (yeast and molds), and for gram-negative bacteria tolerant to bile, the acai capsules had an absence of Salmonella and E. coli. These results indicate no failures during processing or lack of adherence to good manufacturing practices. There is no specific legislation for this type of product; however, it can compare with the United States Pharmacopeia and National Formulary. Açaí is prone to microbiological contamination, mainly by molds, due to the lack of hygiene during harvesting and postharvesting practices $[28,29]$. Molds and yeasts produce spores resistant to the process of dehydration and can grow in conditions of low humidity, representing a health risk due to the mycotoxins they produce [30].

\section{Total Polyphenols and Anthocyanin's}

Total polyphenols content is presented in Table $\mathbf{3}$, expressed on a fresh weight basis for the açaí powder and partially dry weight basis for the pulp, expressed at the same percentage of moisture in the powder for comparison purposes. There was a significant difference between pulp and powder's total polyphenols content. The powder was able to retain $21.6 \%$ of the total polyphenols initially contained in the pulp. Powder açaí contains $46.4 \%$ of the anthocyanins initially contained in the raw material.

The açaí pulp presented a total polyphenol content at around almost five (5) times higher than the powder. The pulp's total anthocyanin content was two (2) times higher than that of the powder. This result shows that the dehydration used affected the total content of the bioactive compounds. However, the values found for both samples are within or above the results reported in the literature. Others [31] indicate that an increase in temperature negatively influenced the capacity of Total phenolic content for açaí pulp and açaí seed from Belen, Brasil. [32] Reported for 56 different açaí samples of the sale in the United States contain much less anthocyanin than what has reported in the literature for fresh or frozen açaí. This study does not distinguish the more susceptible polyphenols to thermic processing neither the influence on antioxidant activity. Antioxidant capacity is concerned with the bioactive molecule's complex nature, thermal tolerance, and synergistic or antagonistic interactions between the mixes. Bioactive compounds depend on the season

Table 2: Results of Microbiological Analysis on Dehydrated Açaí Capsules

\begin{tabular}{|c|c|c|}
\hline Test & log CFU/g & Microbial Limit Requirements (cfu/g or $\mathbf{m L}$ ) \\
\hline \hline Total aerobic microbial count & 407 & $>10^{5}$ \\
\hline Total combined yeasts and molds count & $<10$ Est. & $>10^{3}$ \\
\hline Bile-tolerant Gram-negative bacteria & $<10$ Est. & Absence \\
\hline Salmonella spp. in 10g & Absence & Absence \\
\hline E. coli in 10g & Absence & \\
\hline
\end{tabular}

Table 3: Content of Total Polyphenols and Anthocyanins in Açaí Pulp and Powder

\begin{tabular}{|c|c|c|}
\hline Sample & Total polyphenols mg GAE/100g & Total Anthocyanins mg C3GE/100g \\
\hline \hline Açaí pulp (Partially dry weight) & $4449.5 \pm 159$ & $2021.1 \pm 82$ \\
\hline Açaí powder (Fresh weight) & $962.7 \pm 22.2$ & $938.5 \pm 19.1$ \\
\hline
\end{tabular}

The results are expressed on a wet basis and on a partially dry basis at $8.46 \%$ moisture in mg/100g of sample. GAE $=\mathrm{Gallic}$ acid equivalents, C3GE $=\mathrm{Cyanidine-3-}$ glucoside equivalents. 
and harvest areas, climatic conditions, maturity of the fruit, and storage conditions. In Venezuela, there are still few studies that have evaluated the açaí fruit.

The anthocyanin's content was significantly different between açaí pulp and powder. This reduction is probably due to the applied thermic processing. A significant decrease in anthocyanin's content maybe indicates a decrease in the antioxidant capacity of the powder. Others [33-40] have mentioned that the content of total polyphenols in the açaí corresponds to approximately $96 \%$ of anthocyanins-the vast majority of this percentage represented by two specific anthocyanins, cyanidin-3-glucoside, and cyanidin-3rutinoside. It was observed that the decrease of polyphenols is twice as much as the decrease in total anthocyanins. Maybe the polyphenols have a higher proportion of other thermolabile molecules that do not belong to the anthocyanin category. It could be that they exist other molecules that cause an overestimation in the measurement of polyphenols. Besides, the original polyphenols' original content is very different from the original content of anthocyanins, possibly attributed to extraction methods and accurate methods.

\section{Antioxidant Activity}

The evolution of the antioxidant effect against time shown in Figure 2 indicates that after 30 minutes, reactions still have not stabilized; instead, they reach a plateau at 60 and 80 minutes, respectively. Açaí powder in the constant state reaches a DPPH residual percentage of $58.95 \pm 0.79$, while the pulp in the same state presented a \%RDPPH of $8.334 \pm 0.05$, meaning that there is the powder has a $14.13 \%$ of the original reduction power of the sample.

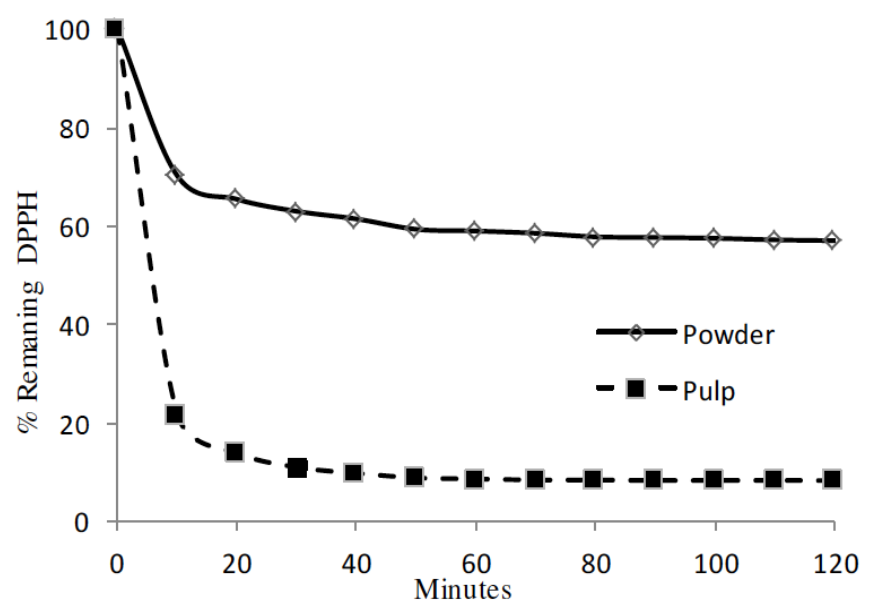

Figure 2: Evolution of the antioxidant effect of açaí pulp and powder against time.
The antioxidant capacity of the dehydrated product decreased significantly. This makes it challenging to establish the linear relationship between the variables (total polyphenols, total anthocyanin's, antioxidant activity) and suggests that there may be complex (synergistic) interaction between the different reducing compounds in the mixture. Some researchers [41] suggest non-phenolic reducing compounds (carotenoids and ascorbic acid) detected by the FolinCiocalteau method. Glucose and fructose [42] present in fruits. Also reports of interactions of vitamin $C<$ $0.1 \mathrm{mg} / 100 \mathrm{~g}$ in total phenols measurement $[27,43]$. If the amount of non-phenolic reducing compounds in the pulp is very high, this will be reflected in a very high antioxidant capacity because the DPPH test is also not very specific. Ascorbic acid is an unstable component [44], so at the end of the raw material processing, when its antioxidant activity is measured, there may be much interference.

\section{Stability Analysis of the Açaí Capsules}

The significant reduction of polyphenols, anthocyanins, and antioxidant capacity (Table 4) indicates that the bioactive components are sensitive to heat even in darkness and the absence of oxygen. The sample was hermetically packaged and placed in a chamber without light. So, the loss of bioactive components that occurred during the dehydration of açaí pulp is mainly attributed to the thermolabile condition of these compounds (even at $37^{\circ} \mathrm{C}$ ). The results indicate that it is preferable to keep the product stored under refrigerated conditions or frozen if possible.

\section{Anthropometric and Biochemical Markers}

In the study, diet supplementation with açaí capsules did not result in changes in weight, BMI, or WHR (Table 5). Because the participants' diets remained the same and therefore their total energy consumption did not change either because the dose and time of consumption of the product were too low to generate a significant change of this type. No significant change in blood glucose levels was observed at the end of the study. The measurement of blood glucose during fasting was used to detect any possible changes in the metabolic conditions of the participants. The oxidative stress increases insulin resistance and is, therefore, the underlying mechanism behind the risk of type 2 diabetes [45,46]. Supplementation with dehydrated açaí did not cause significant changes in cholesterol. 
Table 4: Content of Bioactive Compounds and Antioxidant Capacity in the Dehydrated Açaí Sample at 0 and 90 Days

\begin{tabular}{|c|c|c|c|}
\hline & 0 days & 90 days & Losses \\
\hline \hline Total Polyphenols & $962.7 \pm 22.2 \mathrm{mg} \mathrm{GAE} / 100 \mathrm{~g}$ & $577.4 \pm 11.7 \mathrm{mg} \mathrm{GAE} / 100 \mathrm{~g}$ & $40.02 \%$ \\
\hline Total Anthocyanins & $938.5 \pm 19.1 \mathrm{mg} \mathrm{C} 3 \mathrm{GE} / 100 \mathrm{~g}$ & $341.1 \pm 17.5 \mathrm{mg} \mathrm{C} 3 \mathrm{GE} / 100 \mathrm{~g}$ & $63.65 \%$ \\
\hline VCEAC & $14.07 \pm 0.45 \mathrm{~g} \mathrm{VCE} / 100 \mathrm{~g}$ & $9.98 \pm 0.679 \mathrm{~g} \mathrm{VCE} / 100 \mathrm{~g}$ & $29.05 \%$ \\
\hline TEAC & $643.63 \pm 24.32 \mu \mathrm{mol} \mathrm{TE} / 100 \mathrm{~g}$ & $477.35 \pm 5.87 \mu \mathrm{mol} \mathrm{TE} / 100 \mathrm{~g}$ & $25.83 \%$ \\
\hline
\end{tabular}

Results expressed as an average of 3 replicates \pm standard deviation. AC = Antioxidant Capacity, GAE = Gallic Acid Equivalents, C3GE = Cyanidine-3-Glucoside Equivalents, VCE $=$ Vitamin $\mathrm{C}$ Equivalents and TE $=$ Trolox Equivalents.

Table 5: Average Anthropometric Measurements of Volunteers at the Beginning and End of the Study, BMI Body Mass Index, WHR Waist to Hip Ratio, and Weight

\begin{tabular}{|c|c|c|c|}
\hline Index & Before & After & $\mathbf{p}$ \\
\hline \hline BMI $\left(\mathrm{kg} / \mathrm{m}^{2}\right)$ & $23.69 \pm 4.4$ & $23.58 \pm 4,4$ & 0.170 \\
\hline WHR & $0.878 \pm 0.1$ & $0.873 \pm 0,1$ & 0.136 \\
\hline Weight $(\mathrm{kg})$ & $63.94 \pm 10.7$ & $63.54 \pm 11.2$ & 0.117 \\
\hline
\end{tabular}

Results expressed as the average of the values of all study participants \pm standard deviation.

Low-density lipoprotein (LDL) cholesterol is considered to be atherogenic because LDL is damaged by oxygen-reactive species, or free radicals are absorbed by macrophages, which build upon the endothelial walls as fat spongiform cells during the initial stages of atherosclerotic. The lipid profile is generally used as a biological indicator of the risk of such a condition.

An increase in the antioxidant content should cause in the blood a decrease in LDL or an increase in HDL; however, the dose supplied by the diet with açaí capsules did not generate any significant change in the concentration of LDL, HDL in the blood or the other cholesterol-related indicators (Table 6).

It cannot be argued that the lack of change is since the bioactive compounds in the fruit are not capable of generating such a change. There is evidence that a diet supplemented with açaí generates the expected changes in the lipid profile in populations of rats [8], rabbits [9], and humans [10]. However, in some studies, it was also observed that there was no change in anthropometric parameters or blood biochemistry. However, in some studies, it was also observed that there was no change in anthropometric parameters or blood biochemistry [11]. Another difference is that the studies mentioned above-used açaí pulp preserved by freezing or dehydrated by lyophilization, which guarantees high conservation of the original polyphenol content in the sample.

Another possible explanation for the lack of changes is that the loss of polyphenol content by the heat treatment was not generated a sufficient increase in the blood to generate a decrease in LDL with the

Table 6: Average Blood Glycemia Values and Lipid Indicators of Oxidative Stress in Volunteers at the Beginning and End of the Study

\begin{tabular}{|c|c|c|c|}
\hline Index & Before & After & p \\
\hline \hline Glycemia $\mathrm{mg} / \mathrm{dL}$ & $92.2 \pm 7.3$ & $92.4 \pm 9.8$ & 0.478 \\
\hline Cholesterol $\mathrm{mg} / \mathrm{dL}$ & $175.7 \pm 58.5$ & $179.1 \pm 55.1$ & 0.295 \\
\hline Triglycerides $\mathrm{mg} / \mathrm{dL}$ & $97.6 \pm 47.7$ & $87.7 \pm 35.7$ & 0.118 \\
\hline HDL $\mathrm{mg} / \mathrm{dL}$ & $42.7 \pm 15.4$ & $42.1 \pm 16$ & 0.372 \\
\hline LDL $\mathrm{mg} / \mathrm{dL}$ & $113.48 \pm 57.6$ & $119.46 \pm 50.8$ & 0.175 \\
\hline 8-Isoprostane $(\mathrm{pg} / \mathrm{mL})$ & $159 \pm 48.7$ & $91.6 \pm 29.9$ & $2.17^{*} 10^{-4}$ \\
\hline
\end{tabular}

Results expressed as the average of the values of all study participants \pm standard deviation. 
dose supplied. Possibly the dose given was very low, as studies have shown that a significant amount of polyphenols remains in the dehydrated product and that these have a remaining antioxidant capacity. Therefore, increasing the dose several times may result in a change in the lipid profile. However, the consumption of more than one capsule per meal is likely to result in low acceptability to a potential consumer. It is also possible that the consumption of the dehydrated product may lead to changes in biomarkers that may only be observed after long-term consumption.

Udani et al. [10] used an overweight population whose BMI, WHR, glycemia, and lipid profile values were very high. This population has a condition it is susceptible to the consumption of substances rich in polyphenols. Pala et al. made studies [11] by up of healthy women with standard metabolic indicators. Therefore, this population was probably not as sensitive to the consumption of polyphenols, and for this reason, no changes could see in most biological indicators. This study aimed to use a population composed of older individuals over the age of 32 to ensure a certain amount of oxidative stress injuries resulting from the aging process in humans. However, when analyzing the anthropometric and metabolic indicators of the population, it turns out that most of these have standard values, which is why when executing the intervention study, we find results similar to those of [11].

Of all the biomarkers used in the study, 8isoprostane was the only one in which a significant change was detected, indicating that the product significantly reduced lipid peroxidation in the population analyzed. Lipid peroxidation is the reaction between free radicals and polyunsaturated fatty acids generating lipid peroxides. Fatty acids under free radical attack become a lipid radical with allylic double bonds. These double bonds can combine with oxygen to produce lipid peroxy radicals and ultimately lipid peroxides that usually decompose to form aldehydes (e.g., malonaldehyde) which can cross-link or change the structures of proteins, lipids, carbohydrates, and DNA, ultimately harming an organism in another word, these by-products are themselves, toxic [47].

As these injuries accumulate in the body, over time, they can develop into the following conditions: diabetes mellitus, atherosclerosis, rheumatoid arthritis, ischemia-reperfusion [48], hemolytic anemias, and pulmonary dysfunction [49]. However, it has been suggested that only when lipid peroxidation takes place in uncontrolled free radical chain reactions that overwhelm antioxidant cell protection does lipid peroxidation cause cell damage [49].

Another negative characteristic of lipid peroxides is that they are more hydrophilic than normal unsaturated fatty acids, altering their ability to transfer metabolites through the cell membrane selectively. As a result, excess water may enter the cell, and inflammation may occur, triggering more $\mathrm{O}_{2}^{-}$release, thus contributing to a positive feedback system that facilitates or propagates lipid peroxidation reactions and produces more aldehydes, moving the cell towards destruction [47].

The fact that lipid peroxidation can be decreased by açaí powder (possibly due to its antioxidant content) can translate into a lesser amount of cell damage and interference of the positive feedback system that leads to increased oxidative stress. In short, it could significantly decrease the likelihood of suffering any of the conditions mentioned above.

\section{CONCLUSION}

Acai pulp and powder is a natural alternative for the consumption of bioactive compounds necessary in human nutrition and that are useful in maintaining many functions. In the intervention study, no significant differences were observed between before and after the different biochemical markers with the exception of 8-isoprostane, suggesting that the consumption of dehydrated açaí produces beneficial effects in the analyzed population.

\section{REFERENCES}

[1] Strudwick J, Sobel GL. Uses of Euterpe oleracea Mart. in the Amazon estuary, Brazil. Adv Econ Bot 1988; 6: 225-253

[2] Brondizio ES, Siqueira AD. From extractivists to forest farmers: changing concepts of agricultural intensification and peasantry in the Amazon estuary. Res Econ Anthropology 1997; 18: 233-79.

[3] Schauss A, Jensen G, Wu X. Açaí (Euterpe oleracea). An Amazonian Palm Fruit with Broad Antioxidant and Antiinflammatory Activities. In: Qian M and Rimando A, editors. Flavor and Health Benefits of Small Fruits. Washington, DC: J Am Chem Soc 2010; 213-223. https://doi.org/10.1021/bk-2010-1035.ch013

[4] Haslam E. Che faro senza polifenoli? in: Gross G Hemingway R, YoshidaTakashi, editors. Plant Polyphenols 2: Chemistry, Biology, Pharmacology, Ecology. New York. Kluwer Academic / Plenum Publishers 1999; p. 17-20. https://doi.org/10.1007/978-1-4615-4139-4

[5] Martinez N, Del Mar Camacho M, Martinez JJ. Los compuestos bioactivos de las frutas y sus efectos en la salud. Act Diet 2008;12: 64-8.

https://doi.org/10.1016/S1138-0322(08)75623-2 
[6] Jensen G, Wu X, Patterson K, Barnes J, Carter S, Scherwitz $L$, Beaman $R$, Endres $J$, Schauss $A$. In vitro and in vivo Antioxidant and Anti-inflammatory Capacities of an Antioxidant-Rich Fruit and Berry Juice Blend. Results of a Pilot and Randomized, Double-Blinded, Placebo-Controlled, Crossover Study. J Agric Food Chem 2008; 56: 8326-8333. https://doi.org/10.1021/jf8016157

[7] Mena P, Dominguez-Perles R, Girones-Vilaplana A, Baenas N, Garcia-Viguera C, Villano D. Flavan-3-ols, anthocyanins, and inflammation. IUBMB Life 2014; 66, 745-758. https://doi.org/10.1002/iub.1332

[8] De Souza MO, Silva M, Silva ME, Oliveira R, Pedrosa ML. Diet supplementation with açaí (Euterpe oleracea Mart.) pulp improves biomarkers of oxidative stress and the serum lipid profile in rats. Nutrition 2010; 26: 80410. https://doi.org/10.1016/j.nut.2009.09.007

[9] Feio $C$, Izar $M$, Ihara $S$, Kasmas $S$, Martins $C$, Feio M, Maués L, Borges N, Moreno R, Póvoa R, Fonseca F. Euterpe oleracea (açai) modifies sterol metabolism and attenuates experimentally-induced atherosclerosis. J Atheroscler Thromb 2012; 19: 237-245. https://doi.org/10.5551/jat.11205

[10] Udani J, Singh B, Singh V, Barrett M: Effects of Açai (Euterpe oleracea Mart.) berry preparation on metabolic parameters in a healthy overweight population: A pilot study. Nutr J 2011; 10: 42-45. https://doi.org/10.1186/1475-2891-10-45

[11] Pala D, Barbosa PO, Silva CT, De Souza MO, Freitas FR, Volp AC, Maranhão RC, De Freitas RN. Açaí (Euterpe oleracea Mart.) dietary intake affects plasma lipids, apolipoproteins, cholesteryl ester transfer to high-density lipoprotein, and redox metabolism: a prospective study in women. Clin Nutr 2018; 37: 618-623.

https://doi.org/10.1016/j.clnu.2017.02.001

[12] Rogez H, Akwie SN, Moura FG, Larondelle Y. Kinetic modeling of anthocyanin degradation and microorganism growth during postharvest storage of açaí fruits (Euterpe oleracea). J Food Sci 2012; 77: C13001306.

https://doi.org/10.1111/j.1750-3841.2012.02996.x

[13] A.O.A.C (Official Methods of Analysis). Official Methods of Analysis. Vol.I.17th ed. Association of Analytical Washington. DC. USA 2000.

[14] United States Pharmacopeia and National Formulary. USP 38-NF 33. Rockville, MD: United States Pharmacopeial Convention. 2013.

[15] United States Pharmacopeia and National Formulary. USP 32-NF 27. Rockville, MD: United States Pharmacopeial Convention 2012.

[16] Singleton VL, Rossi J. Colorimetry of Total Phenolics with Phosphomolybdic-Phosphotungstic Acid Reagents. Am. J. Enol. Vitic 1965; 16: 144-158.

[17] Giusti M, Wrolstad R. Characterization and Measurement of Anthocyanins by UV-Visible Spectroscopy. Current Protocols in Food Analytical Chemistry 2001; F1.2.1-F1.2.13. https://doi.org/10.1002/0471142913.faf0102s00

[18] Brand-Williams W, Cuvelier M E, Berset C. Use of free radical method to evaluate antioxidant activity. Lebensm.Wiss. Technol 1995; 28: 25-30.

https://doi.org/10.1016/S0023-6438(95)80008-5

[19] Sánchez-Moreno C. Compuestos polifenólicos: estructura y classificación: presencia en alimentos y consumo: biodisponibilidad y metabolismo. Alimentaria: Revista de tecnología e higiene de los alimentos 2002; 329: 19-28.

[20] Dae-Ok K, Lee KW, Hyong JL, Chang Y. Vitamin C equivalent antioxidant capacity (VCEAC) of phenolic phytochemicals. J Agric Food Chem 2002; 50: 3713-7. https://doi.org/10.1021/jf020071c

[21] World Medical Association. Declaration of Helsinki, 1st (Tokyo) amendment. 1975.
[22] Cameron N, Hiernaux J, Jarman S, Marshall W, Tanner J, Whitehouse R. Anthropometry. In Practical Human Biology, J.S. Weiner, and J.A. Lourie, editors. London: Academic Press 1981, p. 27-52

[23] Statistical Package for the Social Sciences (SPSS) Categories 13.0. Meulman JJ and Heiser WJ SPSS. Inc. Web site at http://www.spss.com or contact. SPSS Inc. Chicago. Illinois; 2012. USA

[24] Moura RS, Ferreira TS, Lopes AA, Pires KM, Nesi R, Resende AC, Souza P J, Da Silva AJ, Valenca S. Effects of Euterpe oleracea Mart. (açaí) extract in acute lung inflammation induced by cigarette smoke in the mouse. Phytomedicine 2012; 19: 262-269.

https://doi.org/10.1016/j.phymed.2011.11.004

[25] Melo PS, Mabe CM, Gonçalves RH, Oliveira De J, Prado A, Matias S. Açaí seeds: An unexplored agro-industrial residue as a potential source of lipids, fibers, and antioxidant phenolic compounds. Ind Crop Prod 2021; 161: 113204. https://doi.org/10.1016/j.indcrop.2020.113204

[26] Franco LB, Zambiazi RC, Vieira CJ. Biocompounds and physical properties of açaí pulp dried by different methods. LWT - Food Sci Technol 2018; 335-340.

https://doi.org/10.1016/j.Iwt.2018.08.058

[27] Schauss A, Wu X, Prior RL, Ou B, Patel D, Huang D, Kababick JP. Phytochemical and nutrient composition of the freeze-dried amazonian palm berry, Euterpe oleraceae Mart. (açaí). J Agric Food Chem 2006; 54: 8598- 8603. https://doi.org/10.1021/jf060976g

[28] Nascimento RJS, Couri S, Antoniassi R, Freitas SP Composição em ácidos graxos do óleo da polpa de açaí extraído com enzimas e com hexano. Revista Brasileira de Fruticultura 2008; 30: 498-502. https://doi.org/10.1590/S0100-29452008000200040

[29] Santos EHF, Figueiredo A, Donzeli VP. Aspectos físicoquímicos e microbiológicos de polpas de frutas comercializadas em Petrolina (PE) e Juazeiro (BA). Braz J Food Technol 2016; 19 e2015089. https://doi.org/10.1590/1981-6723.8915

[30] De Faria C, Modolo R, Moreno H. Plasma 8-Isoprostane as a Biomarker and Applications to Cardiovascular Disease. Biomarkers in Cardiovascular 2016; 467-488. https://doi.org/10.1007/978-94-007-7678-4 31

[31] Rossetto R, Maciel GM, Rampazzo V, Charles I. Acai pulp and seeds as emerging sources of phenolic compounds for enrichment of residual yeasts (Saccharomyces cerevisiae) through biosorption process. LWT 2020; 128: 109447. https://doi.org/10.1016/j.Iwt.2020.109447

[32] Lee J. Anthocyanins of açai products in the United States. NFS Journal 2019; 14-15: 14-21. https://doi.org/10.1016/j.nfs.2019.05.001

[33] Pacheco-Palencia LA, Duncan ChE, Talcot StT. Phytochemical composition and thermal stability of two commercial açaí species, Euterpe oleracea and Euterpe precatoria. Food Chem 2009; 115: 1199-1205. https://doi.org/10.1016/j.foodchem.2009.01.034

[34] Vera V, Hillebrand S, Montilla E, Bobbio F, Winterhalter P. Determination of anthocyanins from acerola (Malpighia emarginata DC.) and açaí (Euterpe oleracea Mart.) by HPLCPDA-MS/MS. J Food Compos Anal 2008; 21:291-299. https://doi.org/10.1016/j.jfca.2008.01.001

[35] Gallori S, Bilia AR, Bergonzi MC, Barbosa WLR, Vincieri FF. Polyphenolic constituents of anthocyanins from the açaí fruit (Euterpe oleracea) Mart Cienc Technol Aliment 2004; 20: 388-390.

[36] Schauss A, Wu X, Prior RL, Ou B, Huang D, Owens J, Agarwal A, Jensen GS, Hart AN, Shanbrom E. Antioxidant capacity and other bioactivities of the freeze-dried amazonian palm berry, Euterpe oleraceae Mart. (açaí). J Agric Food Chem 2006; 54: 8604-8610. https://doi.org/10.1021/jf0609779 
[37] Pozo-Insfran DD, Brenes CH, Talcoot ST. Phytochemical composition and pigment stability of açaí (Euterpe oleracea Mart.). J Agric Food Chem 2004; 52, 1539-1545. https://doi.org/10.1021/jf035189n

[38] Pozo-Insfran DD, Percival SS, Talcott ST. Açaí (Euterpe oleracea Mart.) polyphenolics in their glycoside and aglycone forms induce apoptosis of HL-60 leukemia cells. J Agric Food Chem 2006; 54: 1222-1229. https://doi.org/10.1021/jf052132n

[39] Lichtenthaler R, Rodrigues RB, Maia JG, Papagiannopoulos $M$, Fabricius $H$, Marx F. Total oxidant scavenging capacities of Euterpe oleracea Mart. (Açaí) fruits. Int J Food Sci Nutr 2005; 56:5364. https://doi.org/10.1080/09637480500082082

[40] Carvalho J, Greggi L, Ferro A, Castania J, Vera de R V, Zerlotti A, Pires ML. Evaluation of the genotoxic and antigenotoxic effects after acute and subacute treatments with açaí pulp (Euterpe oleracea Mart) on mice using erythrocytes micronucleus test and the comet assay. Mutat Res 2010; 695: 22-28. https://doi.org/10.1016/j.mrgentox.2009.10.009

[41] Kang J, Thakali K, Xie C, Kondo M, Tong Y, Ou B, Jensen G, Medina M, Schauss A, Wu X. Bioactivities of açaí (Euterpe precatoria Mart.) fruit pulp, superior antioxidant and antiinflammatory properties to Euterpe oleracea Mart. Food Chem 2012; 133: 6717. https://doi.org/10.1016/j.foodchem.2012.01.048

[42] Medina MB. Simple and rapid method for the analysis of phenolic compounds in beverages and grains. J Agric Food Chem 2011; 59: 1565-1571. https://doi.org/10.1021/jf103711c
[43] Aymoto H N, Genovese MI, Lajolo FM. Antioxidant Activity of Dietary Fruits, Vegetables, and Commercial Frozen Fruit Pulps. J Agric Food Chem 2005; 53: 2928-2935. https://doi.org/10.1021/jf047894h

[44] Dasgupta A, Klein K. Fruit Fruits, Vegetables, and Nuts: Good Sources of Antioxidants. In: Elsevier Inc, editors. Antioxidants in Food, Vitamins and Supplements: Prevention and Treatment of Disease. USA 2014; 12: 209-232. https://doi.org/10.1016/C2012-0-02831-1

[45] Wellen KE, Hotamisligil GS. Inflammation, stress, and diabetes. J Clin Investig 2005; 115: 1111-1119. https://doi.org/10.1172/JCl25102

[46] Grattagliano I, Palmieri V, Portincasa P, Moschetta A, Palasciano G. Oxidative stress-induced risk factors associated with the metabolic síndrome: a unifying hypothesis. J Nutr Biochem 2008; 19: 491-504. https://doi.org/10.1016/j.jnutbio.2007.06.011

[47] Alessio H. Lipid peroxidation in healthy and diseased models: influence of different types of exercise. In: Handbook of Oxidants and Antioxidants in Exercise. (Sen C.K, Packer L and Hänninen O. ed.) Elsevier Science, Armsterdam, 2000 115-127. https://doi.org/10.1016/B978-044482650-3/50005-5

[48] Requena JR, Fu MX, Ahmed MU, Jenkins AJ, Lyons TJ, Thorpe SR. Lipoxidation products as biomarkers of oxidative damage to proteins during lipid peroxidation reactions. Nephrol Dial Transplant 1996; 11: 48-53. https://doi.org/10.1093/ndt/11.supp5.48

[49] Sevanian A, Hochstein P. Mechanisms and consequences of lipid peroxidation in biological systems. Annu Rev Nutr 1985; 5: $365-390$ https://doi.org/10.1146/annurev.nu.05.070185.002053

https://doi.org/10.6000/1929-5634.2021.10.01

(C) 2021 Guzmán et al.; Licensee Lifescience Global.

This is an open access article licensed under the terms of the Creative Commons Attribution Non-Commercial License (http://creativecommons.org/licenses/by-nc/3.0/) which permits unrestricted, non-commercial use, distribution and reproduction in any medium, provided the work is properly cited. 